\title{
Morphological characterization of Amiata donkey through Multivariate analyses
}

\author{
Clara Sargentini ${ }^{*}$ (iD), Roberto Tocci ${ }^{1}$ (D), Andrea Martini' ${ }^{1}$ (i), Riccardo Bozzi ${ }^{1}$ \\ ${ }^{1}$ Università degli Studi di Firenze, Dipartimento di Scienze delle Produzioni Agroalimentari e dell'Ambiente (DISPAA) - Sez. Scienze Animali, \\ Firenze, Italy.
}

ABSTRACT - The objective of this study was to evaluate the morphology and biometrics of female Amiata donkeys reared in four different areas of southern Tuscany, Italy, to determine the differentiation degree of animals. Four southern Tuscan areas were investigated: two mountainous zones (East and West Amiata) and two flatter areas (Coastal area and Siena surrounding). Morphology and biometrics of adult female Amiata donkeys were collected to determine the homogeneity of the population. Primitive coat markings typical of the breed (shoulder and leg stripes) were found in Amiata donkey. Jennets from Siena surrounding were more dolichomorphic, while West Amiata individuals were smaller. The Principal Component Analysis and the Discriminant Analysis separated the Siena surrounding jennets from the other populations. This result was confirmed through the heatmap representation. The biometrics found in this research confirm that Amiata donkey is a small-medium sized breed suitable for different purposes.

Key Words: biometrics, discriminant analysis, donkeys, geographical diversity, morphology, PCA

\section{Introduction}

The Amiata donkey is a Tuscan endangered breed placed in the Local Equine Population List (AIA, 2008). This donkey originates from Mount Amiata, located in Siena and Grosseto provinces, in southern Tuscany, Italy. The shoulder stripe (St. Andrew cross) and the more or less visible leg stripes (Figure 1) are features of the Amiata donkey ancestors: the Equus asinus africanus and the Equus asinus somaliensis (Arzilli, 2006). The breed was

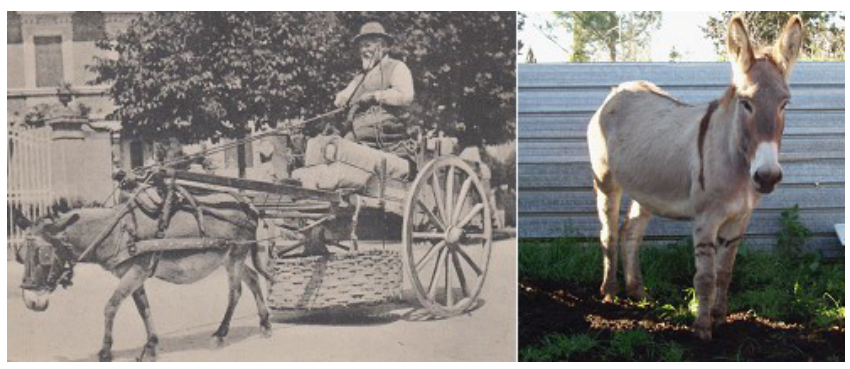

Figure 1 - Amiata donkey in the past and in the present.

Received: January 27, 2018

Accepted: May 24, 2018

*Corresponding author: clara.sargentini@unifi.it

Copyright $\odot 2018$ Sociedade Brasileira de Zootecnia. This is an Open Access article distributed under the terms of the Creative Commons Attribution License (http://creativecommons.org/licenses/by/4.0/), which permits unrestricted use, distribution, and reproduction in any medium, provided the original work is properly cited. used in the past as a pack animal on farms and in mines, which are rather diffused in this area. The Amiata donkey is now used for milk production (Martini et al., 2014; Ragona et al., 2016), onotherapy (Camillo, 2011), and trekking (Sargentini et al., 2009; 2012). This breed can also valorize marginal and minor historical and touristic sites through the transport of materials and garbage collection (Sargentini et al., 2009; 2012).

However, the Amiata breed is now biometrically inhomogeneous because of the scarce selective breeding performed in the last fifty years. On this basis, this study was carried out to evaluate the morphology and biometrics of female Amiata donkeys reared in four areas of southern Tuscany to determine the differentiation degree of animals. This work will allow for the protection and valorization of the Amiata donkey and better understanding of the proper aptitudes of this breed (milk production, trekking, onotherapy, garbage collection, and farmhouse), with economic impacts on farms and territory.

\section{Material and Methods}

The studied area is located in the provinces of Grosseto and Siena, Italy. Four geographical areas were considered: Coastal area, East Amiata, Siena surrounding, and West Amiata (Figure 2). The Coastal area involves the municipalities of Magliano in Toscana, Massa Marittima, 
and Suvereto; East Amiata area includes the municipalities of Castell'Azzara, Piancastagnaio, and Abbadia San Salvatore; the Siena surrounding area involves the municipality of Monticiano; and the West Amiata area, in the past a mine zone where the donkeys were used as pack and draft animals, includes the municipalities of Arcidosso, Castel del Piano, Cinigiano, Roccalbegna, Santa Fiora, Seggiano, and Semproniano. Mount Labbro is one of the highest mounts of this area, and has two natural Parks: Riserva Naturale del Monte Labbro and Parco Faunistico dell'Amiata, where the donkeys are reared.

Forty-two adult female Amiata donkeys were used: 13 in the Coastal area, 10 in East Amiata, 10 in Siena surrounding, and nine in West Amiata. All procedures involving the animals were conducted in accordance with the local ethics committee laws and regulations as regards care of animals: AWIN Welfare Assessment Protocol For Donkeys, 2015 (10.13130/AWIN_donkeys_2015) and Directives 86/609/EEC and 2010/63/EU Protection of animals used for scientific purposes.

To determine the coat signs, we performed a resource selection analysis comparing their presence (Yes) or absence (No), in which statistical inferences were based on the Chi-squared test.

The morphological traits evaluated on the animals were the dovetail (a dorsal/shoulder stripe forming a cross), leg stripes, radial stripes on the pastern and/or fetlock (zippers) (Figure 3), and collar buttons (small black spots on the side of the neck) (Figure 4).

The following measurements (Figure 5) were recorded: height at withers, height at croup, barrel height, barrel

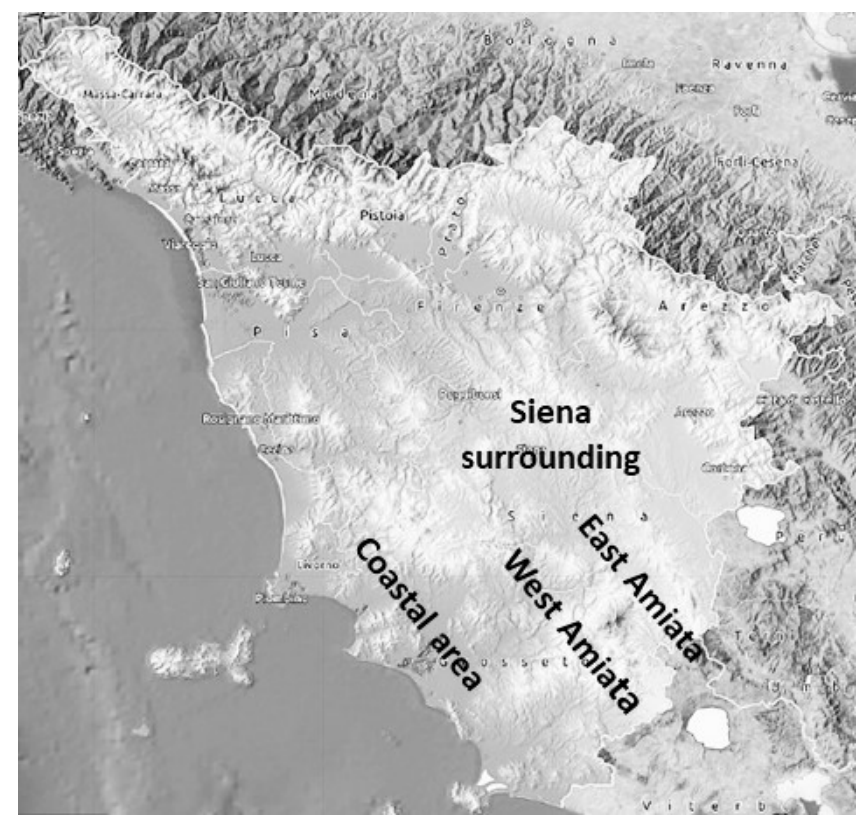

Figure 2 - Map of Tuscany showing sampling areas of the study. width, barrel length, barrel circumference, chest width, trunk length, croup length, bi-iliac width, bitrochanteric width, bi-ischial width, foreshank circumference, hind shank circumference, arc length, neck length, withers-tocroup distance, loin length, withers length, arm length, forearm length, foreshank length, thigh length, gaskin length, pastern length, leg length, and ear length. The following biometric indices were calculated in accordance with Catalano (1984) and Meregalli (1980): relative length trunk, thoracic height index, barrel circumference:height at withers ratio, lateral body conformation, transverse body conformation, lateral trunk conformation, thoracic index, body index (length/barrel circumference $\times 100$ ), and dactyl-thoracic index.

Percentages of morphological characteristics in jennets of the four geographical areas were calculated. For each measure and somatic index the main descriptive statistics (median, mean and standard deviation) were calculated. Jennet biometric characteristics of different geographical regions were estimated through Kruskal-Wallis nonparametric test using SAS (Statistical Analysis System, version 10.0.2) software. Non-parametric Dunn's Multiple Comparison Procedures compared the groups. Both for the Kruskal-Wallis test and for the Dunn's procedure, the level of significance chosen was 0.05 .

The degrees of similarity between donkey biometrics in the four areas were studied through Principal Component Analysis (PCA) using SAS software. The number of factors to rotate was chosen following the eigenvalues-greater-than-one rule proposed by Kaiser (1960), applying the Varimax rotation, which allows

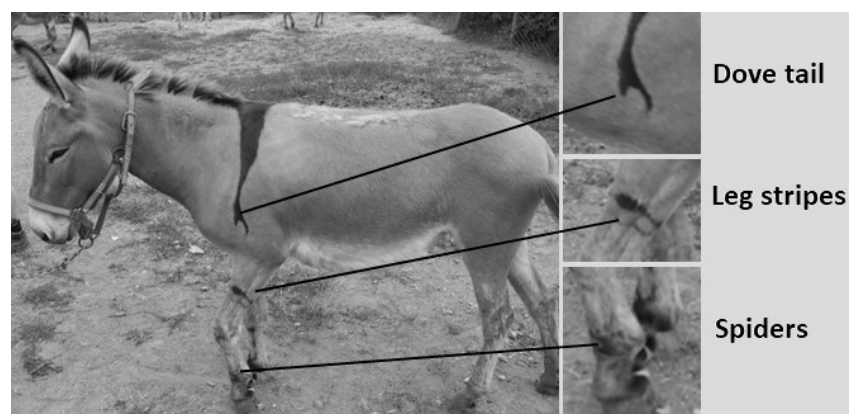

Figure 3 - Coat markings: dove tail; leg stripes; and spiders.

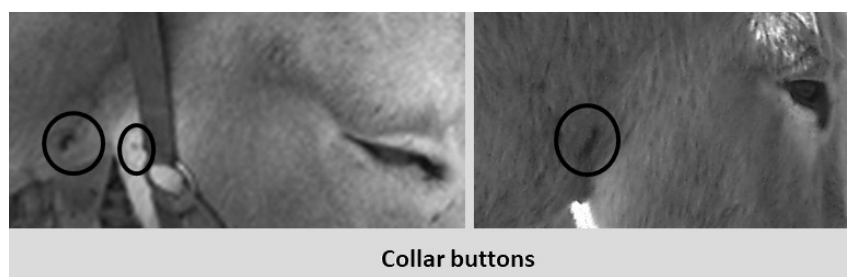

Figure 4 - Coat markings: collar buttons. 
the transformation of the solution so that the Rotated Component Matrix can be relatively easy to understand (Abdi and Williams, 2010). Loadings and score plots for the first three principal components (PC1, PC2, and PC3) were performed to visualize the jennet biometrics and distribution of individuals in the areas.

Discriminant Canonical Analysis was also applied on biometric data and the distance between groups was used to construct the graphic representation of centroid distances. Furthermore, squared distances between all arrays were used to draw a heatmap (Haarman et al., 2015), which is a graphical representation of data that uses a system of colorcoding to represent different values. Both Discriminant Canonical Analysis and the heatmap were performed through SAS software.

\section{Results}

All jennets showed typical characteristics of the breed, having a grey coat with shoulder belt (shoulder stripe $x$ dorsal stripe) and healthy and dark hoof. Some individuals showed characteristics identified as representative of the breed (Sargentini et al., 2009) such as dovetail, collar buttons, leg stripes, and zippers. Dovetail, leg stripes, and zippers were significant in the likelihood ratio and Pearson's chi-squared tests (Table 1): ten jennets (24\% of the total population) displayed dovetail (four in Coastal area, two in East Amiata, two in Siena surrounding, and two in West Amiata); twenty-six (62\%) showed collar buttons (six in Coastal area, six in East Amiata, seven in Siena surrounding, seven in West Amiata), twenty-eight jennets $(66.67 \%$ of the total population) displayed leg strips (eight in Coastal area, three in East Amiata, eight in Siena surrounding, nine in West Amiata), and six animals (14.28\% of the total population) showed zippers (one in Coastal area and five in East Amiata).

Descriptive statistics (mean and standard deviation) of biometrics and body indices in different geographical areas are shown in Tables 2 and 3. The results of KruskalWallis test for the biometrics were shown in Table 4: the chi-square indicated that all considered biometrics were different among geographical areas. Significant results of the nonparametric Dunn's test Pairwise comparison is shown in Table 5.

In comparison with West Amiata jennets, Coastal area and the East Amiata jennets had different height at withers and height at croup (Table 5), which show higher average values for both measures (Table 2).

If compared with West Amiata animals, Coastal area jennets showed different withers-to-croup distance, arm length, forearm length, and gaskin length (Table 5) and higher average values for these measures (Table 2).
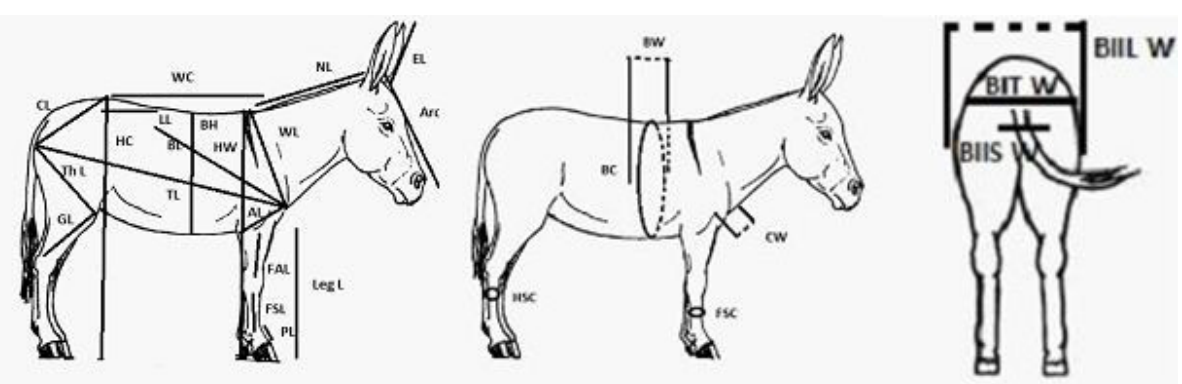

HW - height at withers; HC - height at croup; BH - barrel height; BW - barrel width; BL - barrel length; BC - barrel circumference; CW - chest width; TL - trunk length; CL - croup length; BIIL W - bi-iliac width; BIT W - bitrochanteric width; BIIS W - bi-ischial width; FSC - foreshank circumference; HSC - hind shank circumference; Arc - arc length; NL neck length; WC - withers-to-croup distance; LL - loin length; WL - withers length; AL - arm length; FAL - forearm length; FSL - foreshank length; Th L - thigh length; GL - gaskin length; PL - pastern length; Leg L - leg length; EL - ear length.

Figure 5 - Jennet biometrics.

Table 1 - Distribution of coat signs in Amiata jennets

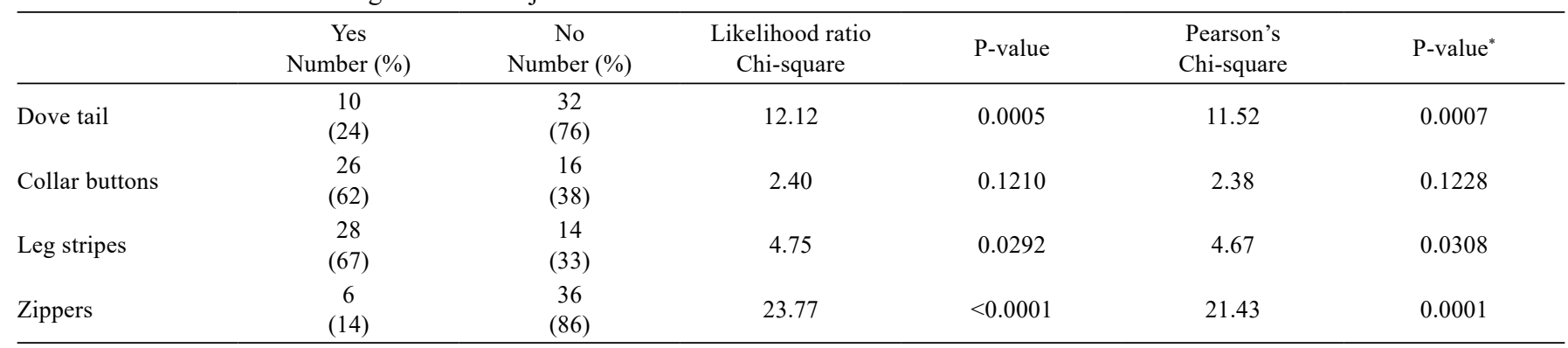

\footnotetext{
${ }^{*}$ Significance level $(\alpha=0.05)$
} 
East Amiata jennets had different loin length than Coastal area donkeys (Table 5), which also showed lower mean value for this measure (Table 2). East Amiata jennets were different from West Amiata donkeys for trunk length, loin length, gaskin length, pastern length, and leg length (Table 5); these latest measures were higher in East Amiata animals (Table 2).

If compared with Coastal area jennets, Siena surrounding individuals showed different barrel width, croup length, loin length, thoracic height index, and barrel circumference:height at withers ratio (Table 5) and higher average values for these measures (Table 2) and these indices (Table 3). In comparison with East Amiata jennets, Siena surrounding individuals had different chest width, bi-ischial width, and foreshank length (Table 5), which showed higher average values for these measures (Table 2). Finally, if compared with West Amiata jennets, Siena surrounding individuals had different chest width, croup length, foreshank length, gaskin length, and leg length (Table 5), which showed higher average values for these measures (Table 2).

In comparison with Siena surrounding and Coastal area jennets, West Amiata individuals showed different arc

Table 2 - Descriptive statistics: measures of adult jennet reared in different Tuscan areas (cm mean \pm SD)

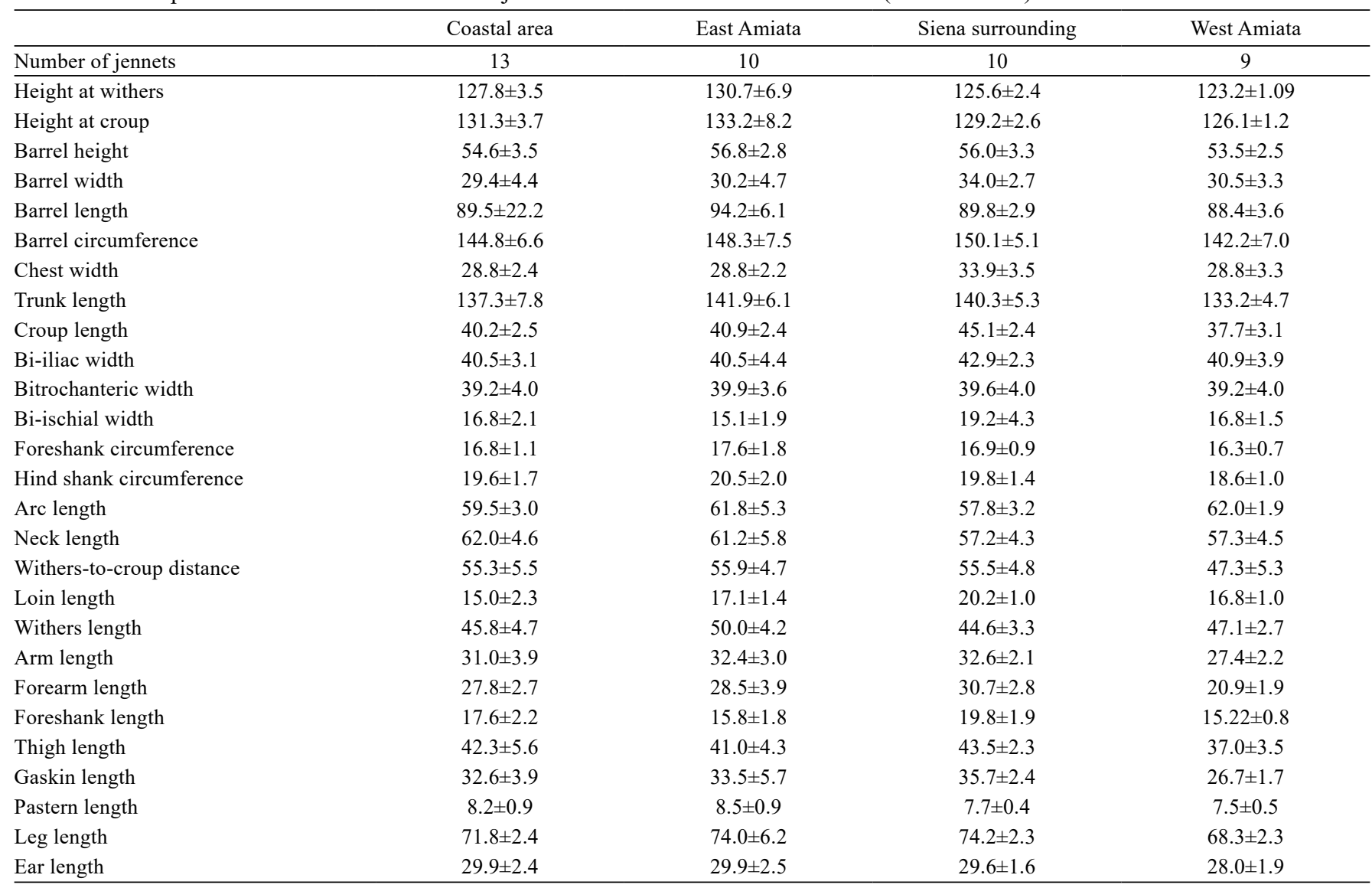

SD - standard deviation.

Table 3 - Descriptive statistics: body indices of adult jennets reared in different Tuscan areas (mean \pm SEM)

\begin{tabular}{|c|c|c|c|c|}
\hline & Coastal area & East Amiata & Siena surrounding & West Amiata \\
\hline Relative length trunk & $107.5 \pm 5.9$ & $108.7 \pm 4.5$ & $111.7 \pm 4.4$ & $108.1 \pm 3.5$ \\
\hline Thoracic height index & $42.7 \pm 2.2$ & $43.5 \pm 0.9$ & $44.6 \pm 2.3$ & $43.4 \pm 2.0$ \\
\hline BC:HW & $113.4 \pm 4.8$ & $113.6 \pm 6.1$ & $119.5 \pm 3.5$ & $115.4 \pm 5.4$ \\
\hline Transverse body conformation & $70.0 \pm 9.2$ & $72.0 \pm 3.0$ & $71.51 \pm 2.4$ & $71.8 \pm 2.7$ \\
\hline Lateral trunk conformation & $39.9 \pm 3.0$ & $40.0 \pm 1.4$ & $40.0 \pm 3.0$ & $40.1 \pm 1.5$ \\
\hline Dactyl-thoracic index & $11.6 \pm 0.5$ & $11.9 \pm 1.0$ & $11.3 \pm 0.7$ & $11.4 \pm 0.5$ \\
\hline
\end{tabular}

$\mathrm{BC}: \mathrm{HW}$ - barrel circumference:height at withers ratio; SEM - standard error of the mean.

${ }^{1}($ length/barrel circumference $\times 100)$. 
length and loin length, respectively (Table 5); West Amiata donkeys showed higher average values for arc while loin length had lower average values.

Seven eigenvalues were significant, with the Kaiser test explaining 75.87 of the total variability and the first three components absorbing 33.4, 13.2, and 9.08\% of the variance (Table 6). Factor scores of the biometrics after Varimax rotation (Table 7) allowed for the identification of animals from the different areas. Factor 1 explained $15.6 \%$ of the variance, and the most influential parameters were height at withers, height at croup, and some limb measurements (withers length, pastern length, and leg length). In factor 2 , which explained $14.9 \%$ of the variance, the most representative parameters were barrel, pelvis, and trunk lengths. Factors 3 and 4 explained 12.5 and $11.1 \%$ of the variance, respectively, and the most influential measurements were croup length and the lengths of forearm, foreshank, thigh, gaskin, and leg for Factor 3; and the lengths of barrel, neck, withers to croup, forearm, thigh, and leg for Factor 4. Other factors explained less than 10\% of the variance.

The loadings plot of the first two principal components (Figure 6) reported all the considered parameters on the right side, while in the score plot, Siena surrounding had the best identified jennet population (Figures 7 and 8). The situation for the other groups is less clear, with Coastal area and East Amiata jennets overlapping on the right side (Figures 7 and 8). Principal Component 3 identified the West Amiata population (Figure 9).

Table 4 - Kruskal-Wallis test for the measures and indices of adult jennets reared in different Tuscan areas $(\mathrm{DF}=3)$

\begin{tabular}{|c|c|c|}
\hline & Chi-square & Prob \\
\hline Height at withers & 15.387 & $0.0015^{*}$ \\
\hline Height at croup & 12.874 & $0.0049 *$ \\
\hline Barrel height & 7.344 & 0.0617 \\
\hline Barrel length & 4.357 & 0.2254 \\
\hline Barrel circumference & 7.560 & 0.0560 \\
\hline Chest width & 14.237 & $0.0026^{*}$ \\
\hline Croup length & 20.489 & $<0.0001^{*}$ \\
\hline Bi-iliac width & 3.704 & 0.2952 \\
\hline Bitrochanteric width & 0.444 & 0.9360 \\
\hline Bi-ischial width & 11.450 & $0.0095^{*}$ \\
\hline Foreshank circumference & 4.905 & 0.1789 \\
\hline Hind shank circumference & 5.384 & 0.1457 \\
\hline Loin length & 25.713 & $<0.0001 *$ \\
\hline Withers length & 8.834 & $0.0316^{*}$ \\
\hline Arm length & 15.326 & $0.0016^{*}$ \\
\hline Forearm length & 23.949 & $<0.0001^{*}$ \\
\hline Foreshank length & 20.628 & $0.0001 *$ \\
\hline Thigh length & 10.297 & $0.0162 *$ \\
\hline Gaskin length & 19.195 & $0.0002 *$ \\
\hline Pastern length & 9.482 & $0.0235^{*}$ \\
\hline Leg length & 16.205 & $0.0010^{*}$ \\
\hline Ear length & 4.380 & 0.2233 \\
\hline Relative length trunk & 5.442 & 0.142 \\
\hline
\end{tabular}

$\mathrm{BC}: \mathrm{HW}$ - barrel circumference:height at withers ratio; DF - degree of freedom.

${ }^{1}$ (length/barrel circumference $\times 100$ ).

Significance level $(\mathrm{P}<0.05)$ 
Table 5 - Dunn's Multiple Comparisons Procedure - Pairwise Comparisons significantly different

\begin{tabular}{|c|c|}
\hline Parameter & Significantly different \\
\hline Height at withers & Coastal area/West Amiata* - East Amiata/West Amiata* \\
\hline Height at croup & Coastal area/West Amiata* - East Amiata/West Amiata* \\
\hline Barrel width & Siena surrounding/Coastal area* \\
\hline Trunk length & East Amiata /West Amiata* \\
\hline Croup length & Siena surrounding/Coastal area* - Siena surrounding/West Amiata \\
\hline Bi-ischial width & Siena surrounding/ East Amiata * \\
\hline Withers-to-croup distance & Coastal area/West Amiata* \\
\hline Loin length & East Amiata /Coastal area* - Siena surrounding/Coastal area* - West Amiata/Coastal area* \\
\hline Withers length & East Amiata/Coastal area* \\
\hline Arm length & Coastal area/West Amiata* \\
\hline Forearm length & Coastal area/West Amiata* \\
\hline Foreshank length & Siena surrounding/ East Amiata* - Siena surrounding/West Amiata* \\
\hline Leg length & East Amiata /West Amiata* - Siena surrounding/West Amiata* \\
\hline Thoracic height index & Siena surrounding/Coastal area* \\
\hline $\mathrm{BC}: \mathrm{HW}$ & Siena surrounding/Coastal area* \\
\hline
\end{tabular}

$\mathrm{BC}: \mathrm{HW}$ - barrel circumference:height at withers ratio.

*Significance level $(\mathrm{P}<0.05)$.

Table 6 - Eigenvalues and variability percentage of Amiata jennet biometrics

\begin{tabular}{lcccc}
\hline No. & Eigenvalue & Percentage & $\begin{array}{c}\text { Cumulative } \\
\text { percentage }\end{array}$ & $\begin{array}{c}\text { Kaiser test } \\
\text { Significance }\end{array}$ \\
\hline 1 & 9.02 & 33.39 & 33.39 & $*$ \\
2 & 3.55 & 13.17 & 46.56 & $*$ \\
3 & 2.45 & 9.06 & 55.62 & $*$ \\
4 & 1.67 & 6.19 & 61.82 & $*$ \\
5 & 1.43 & 5.30 & 67.12 & $*$ \\
6 & 1.28 & 4.73 & 71.85 & $*$ \\
7 & 1.09 & 4.02 & 75.87 & $*$ \\
8 & 0.96 & 3.57 & 79.45 & NS \\
9 & 0.78 & 2.91 & 82.36 & NS \\
10 & 0.66 & 2.46 & 84.82 & NS \\
\hline
\end{tabular}

NS - not significant.

* Significant when eigenvalue $\geq 1$

Canonical Discriminant Analysis (Table 8) identified three statistically significant canonical variables (Wilk's lambda $=0.00063)$, which accounted for $78.38($ CAN1), 12.80 (CAN2), and $8.81 \%$ (CAN3) of the total variation. The canonical correlations were $0.98,0.93$, and 0.90 for CAN1, CAN2, and CAN3, respectively. The main discriminant parameters for CAN1 were chest width, croup length, loin length, and some limb lengths (forearm and foreshank lengths), whereas for CAN2, they were height at withers and height at croup. The biplot of Canonical Discriminant Analysis (Figure 10) showed that CAN1 discriminates the Siena surrounding population from the other three groups, situated on the left side of the plot even if not overlapped, and CAN2 discriminated the East Amiata population. The population means (group centroids) were 1.27, 1.90, 3.58, and 1.12 for Coastal area, East Amiata, Siena surrounding, and West Amiata, respectively.

Squared distances among donkey populations, represented by a heatmap (Figure 11), distinguished five groups. Siena surrounding individuals clustered together even if one individual was placed as a separate group. The remaining populations clustered separately, with two West Amiata animals included in the Coastal area group. The Siena surrounding population was more distant from other groups, while the other three groups were closer, with Coastal area and West Amiata donkeys as the nearest clusters.

\section{Discussion}

The characteristics of coat color and healthy hooves found in this study confirmed the findings of previous studies concerning morphology and hoof characteristics of Amiata donkey (Sargentini et al., 2009; 2012). As already stated by the same authors (Sargentini et al., 2009), signs on legs (stripes and zippers) seem to be a peculiar trait of the breed, whereas dovetail and neck buttons are less representative. Dorsal and leg stripes are considered primitive markings of the species (Johnson and Johnson, 2008), and coat features of the Amiata donkey met those of the domestic donkey ancestor, the African wild ass (Equus asinus atlanticus), already extinct in Roman times (Kugler et al., 2008). The presence of these primitive markings on the Amiata donkey could be a sign of low selection pressure 
in this breed, contrary to what is found in breeds for mule production, for which the selection pressure is stronger (Kugler et al., 2008).

East Amiata and Coastal area had the tallest animals, West Amiata had the smallest, while the animals of Siena surrounding were longer and more dolichomorphic.

Animals of the different areas were morphologically different for body height and length, whereas the basin width was more similar between populations. Siena surrounding jennets were longer, with longer limbs, seeming thus more suitable for saddle and trekking because of their longer back, larger chest, and large barrel. A large chest, found in Siena surrounding individuals, indicates a respiratory type suitable for dynamic activities (Catalano, 1984), whereas a larger size may favor milk production (Civardi, 2004).

West Amiata individuals were shorter, likely due to adverse mountainous conditions (Lenfant, 1973; Jackowski, 2007), considering that the highest peaks of Mount Amiata are in that region. All considered populations showed similar body indices. Only the Siena surrounding population, having greater thorax development, showed a different ratio between barrel circumference and height at withers and thoracic height index.
Height at withers, barrel circumference, and foreshank circumference met the standards for the Amiata donkey breed (AIA, 2013). All animals of this study were larger than the adult females deriving from an Ethiopian (Kefena et al., 2011) and a Czech donkey population (Kost'uková et al., 2015). However, when compared with Romagnolo donkey (Beretti et al., 2005), the Amiata donkey showed lower height at withers and barrel circumference and similar foreshank circumference. The studied animals presented morphological features like those analyzed by Cecchi et al. (2007) in female Amiata donkeys. The biometrics indicated small-medium-sized animals suitable for onotherapy (Karatosidi et al., 2013), for which a height of 130-140 cm favors human approach in pet therapy (Samorì, 2017).

Factor 1 identified the animals mainly for the heights; factor 2 for the widths; and factor 3 for the limb lengths. Siena surrounding jennets were mainly identified for limb, pelvis, and barrel measurements. Coastal area and East Amiata jennets were identified for the heights and for some limb measurements. In a study performed on Ethiopian donkeys (Kefena et al., 2011), the parameters that best identified the different populations were the heights at withers, at croup, and at back, and trunk length.

Table 7 - Varimax rotation factor scores for the seven-factor model for biometrics

\begin{tabular}{|c|c|c|c|c|c|c|c|}
\hline & Factor 1 & Factor 2 & Factor 3 & Factor 4 & Factor 5 & Factor 6 & Factor 7 \\
\hline$\%$ & 15.6 & 14.9 & 12.5 & 11.1 & 7.95 & 7.42 & 6.39 \\
\hline Height at withers & $0.79 *$ & 0.26 & 0.26 & 0.24 & -0.11 & 0.08 & 0.24 \\
\hline Height at croup & $0.77 *$ & 0.22 & 0.28 & 0.19 & -0.02 & 0.17 & 0.31 \\
\hline Barrel height & $0.54 *$ & $0.40 *$ & 0.26 & -0.13 & 0.12 & 0.41 & 0.12 \\
\hline Barrel width & 0.02 & $0.80 *$ & 0.19 & 0.09 & $0.33 *$ & 0.004 & 0.14 \\
\hline Barrel length & $0.40 *$ & $0.45^{*}$ & -0.28 & $0.56^{*}$ & 0.24 & 0.13 & -0.006 \\
\hline Barrel circumference & 0.19 & $0.79 *$ & 0.27 & 0.16 & 0.16 & 0.05 & -0.13 \\
\hline Chest width & -0.18 & $0.32 *$ & 0.30 & 0.15 & $0.68 *$ & 0.12 & -0.008 \\
\hline Trunk length & 0.23 & $0.60 *$ & 0.13 & 0.57 & 0.13 & 0.19 & -0.04 \\
\hline Croup length & -0.02 & 0.27 & $0.55 *$ & 0.25 & 0.28 & -0.04 & -0.35 \\
\hline Bi-iliac width & 0.22 & $0.77 *$ & 0.11 & 0.04 & 0.19 & -0.01 & 0.08 \\
\hline Bitrochanteric width & 0.04 & $0.73 *$ & -0.20 & 0.15 & -0.08 & 0.25 & -0.04 \\
\hline Bi-ischial width & -0.08 & 0.18 & -0.01 & 0.12 & $0.75^{*}$ & -0.05 & 0.15 \\
\hline Foreshank circumference & $0.47 *$ & $0.43 *$ & 0.12 & 0.19 & 0.01 & $0.52 *$ & 0.14 \\
\hline Hind shank circumference & $0.33^{*}$ & $0.33 *$ & 0.19 & 0.17 & -0.13 & $0.71 *$ & 0.05 \\
\hline Arc length & 0.27 & 0.10 & -0.12 & 0.02 & 0.04 & 0.03 & $0.75^{*}$ \\
\hline Neck length & 0.27 & 0.04 & 0.13 & $0.61 *$ & -0.18 & 0.13 & $0.38 *$ \\
\hline Withers-to-croup distance & -0.01 & 0.18 & 0.29 & $0.76^{*}$ & 0.05 & 0.23 & -0.06 \\
\hline Loin length & 0.24 & 0.08 & 0.14 & -0.19 & $0.72 *$ & 0.05 & $-0.40^{*}$ \\
\hline Withers length & $0.73 *$ & 0.11 & -0.24 & -0.11 & -0.09 & 0.27 & -0.09 \\
\hline Arm length & 0.22 & 0.37 & 0.10 & 0.61 & 0.09 & 0.13 & $-0.43^{*}$ \\
\hline Forearm length & 0.21 & 0.13 & $0.65^{*}$ & $0.34 *$ & -0.05 & -0.17 & $-0.47 *$ \\
\hline Foreshank length & -0.07 & 0.20 & $0.86^{*}$ & -0.05 & 0.05 & 0.02 & -0.11 \\
\hline Thigh length & 0.05 & 0.003 & $0.48^{*}$ & $0.51 *$ & $0.33 *$ & 0.18 & 0.09 \\
\hline Gaskin length & 0.23 & -0.08 & $0.78^{*}$ & 0.22 & 0.11 & 0.27 & 0.12 \\
\hline Pastern length & $0.84 *$ & 0.01 & -0.08 & 0.16 & 0.006 & 0.17 & -0.03 \\
\hline Leg length & $0.62 *$ & 0.09 & $0.49 *$ & $0.32 *$ & 0.17 & -0.07 & 0.03 \\
\hline Ear length & 0.22 & -0.02 & -0.03 & 0.28 & 0.13 & $0.74 *$ & -0.009 \\
\hline
\end{tabular}

${ }^{*}$ Significant coefficient of correlation. 
Table 8 - Raw canonical coefficient of canonical discriminant functions

\begin{tabular}{|c|c|c|c|}
\hline & Canon[1] & Canon[2] & Canon[3] \\
\hline Height at withers & -0.02 & $-0.59 *$ & 0.12 \\
\hline Height at croup & 0.01 & $-0.49^{*}$ & 0.19 \\
\hline Barrel height & 0.24 & $-0.32 *$ & -0.03 \\
\hline Barrel length & 0.03 & -0.28 & -0.08 \\
\hline Barrel circumference & $0.38 *$ & -0.21 & 0.03 \\
\hline Croup length & $0.69^{*}$ & -0.10 & 0.21 \\
\hline Bi-iliac width & 0.26 & 0.12 & -0.006 \\
\hline Bitrochanteric width & 0.04 & -0.06 & -0.03 \\
\hline Bi-ischial width & $0.34 *$ & $0.34 *$ & 0.17 \\
\hline Foreshank circumference & 0.11 & $-0.37^{*}$ & 0.004 \\
\hline Hind shank circumference & 0.16 & $-0.38^{*}$ & 0.05 \\
\hline Loin length & $0.73^{*}$ & 0.13 & $-0.30^{*}$ \\
\hline Withers length & -0.19 & -0.35 & $-0.30^{*}$ \\
\hline Arm length & $0.37 *$ & $-0.40^{*}$ & 0.22 \\
\hline Forearm length & $0.55^{*}$ & $-0.42 *$ & $0.43 *$ \\
\hline Foreshank length & $0.55^{*}$ & 0.14 & $0.47 *$ \\
\hline Thigh length & $0.32 *$ & -0.18 & $0.39 *$ \\
\hline Gaskin length & $0.49 *$ & $-0.35^{*}$ & $0.34 *$ \\
\hline Pastern length & -0.07 & $-0.49^{*}$ & 0.12 \\
\hline Leg length & $0.39 *$ & $-0.38^{*}$ & 0.15 \\
\hline Ear length & 0.10 & -0.26 & 0.24 \\
\hline Eigenvalues & 38.85 & 6.35 & 4.37 \\
\hline
\end{tabular}

Lambda Wilk's test: Value 0.00063; FApprox: 4.8632; DF Numb: 81; DF Den: 36.77 Prob $>\mathrm{F}<.0001$

DF - degree of freedom.

* Significant coefficient of correlation.

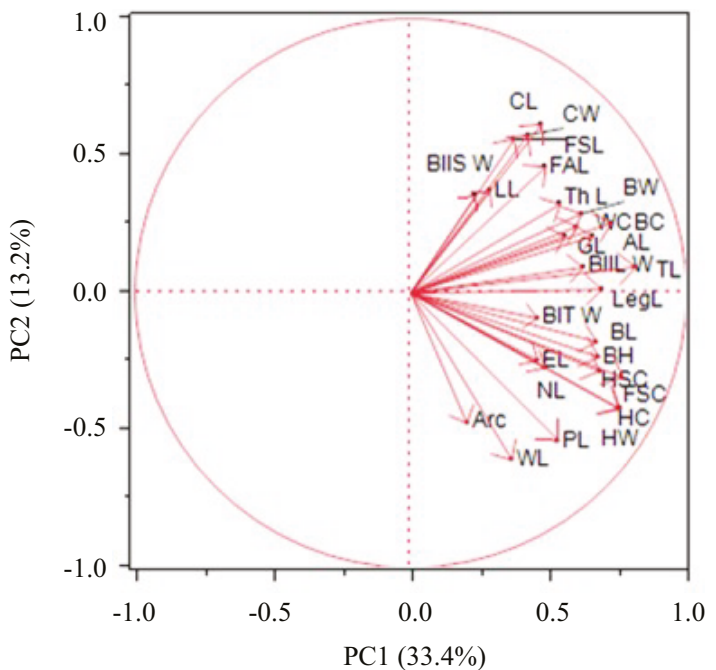

PC - Principal Component; HW - height at withers; HC - height at croup; BH barrel height; BW - barrel width; BL - barrel length; BC - barrel circumference; $\mathrm{CW}$ - chest width; TL - trunk length; CL - croup length; BIIL W - bi-iliac width; BIT W - bitrochanteric width; BIIS W - bi-ischial width; FSC - foreshank circumference; HSC - hind shank circumference; Arc - arc length; NL - neck length; WC - withersto-croup distance; LL - loin length; WL - withers length; AL - arm length; FAL forearm length; FSL - foreshank length; Th L - thigh length; GL - gaskin length; PL pastern length; Leg L - leg length; EL - ear length.

Figure 6 - Load plot of jennet biometrics for areas: PC1 vs PC2.

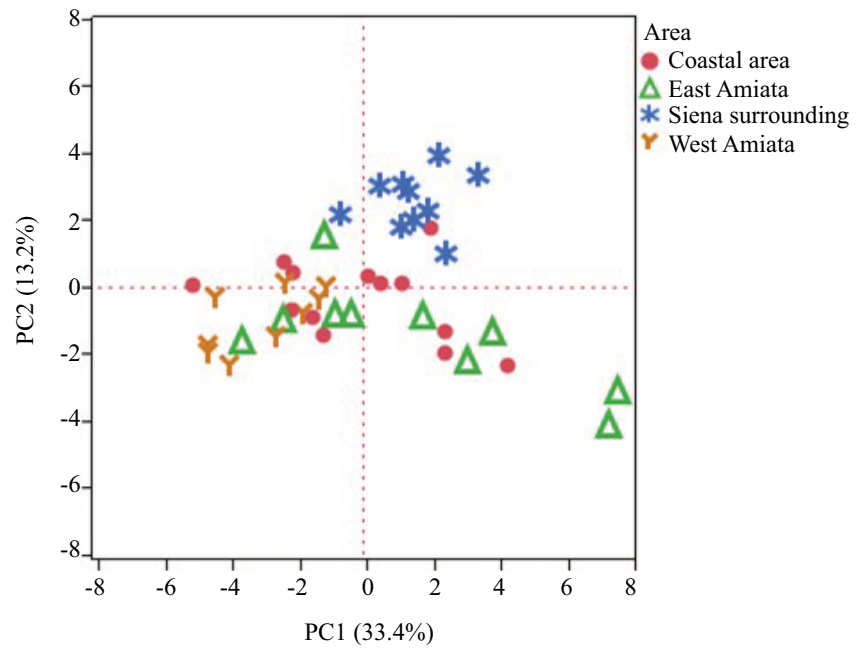

PC - Principal Component.

Figure 7 - Score plot of jennet biometrics for areas: PC1 vs PC2. 
Canonical variable 1 (CAN 1) easily discriminated the Siena surrounding animals, which differed markedly from the other populations. Siena surrounding jennets had longer backs and larger chests than the other groups. On the contrary, in a research study on Ethiopian jennets (Kefena et al., 2011), the Abyssinian population was discriminated by CAN 1 mainly for body length and foreleg length. Heatmap distances confirmed that the Siena surrounding population was distant from the other donkeys; East Amiata animals showed intermediate biometrics, whereas West Amiata and Coastal area groups were more similar because of the small geographical distance between areas.

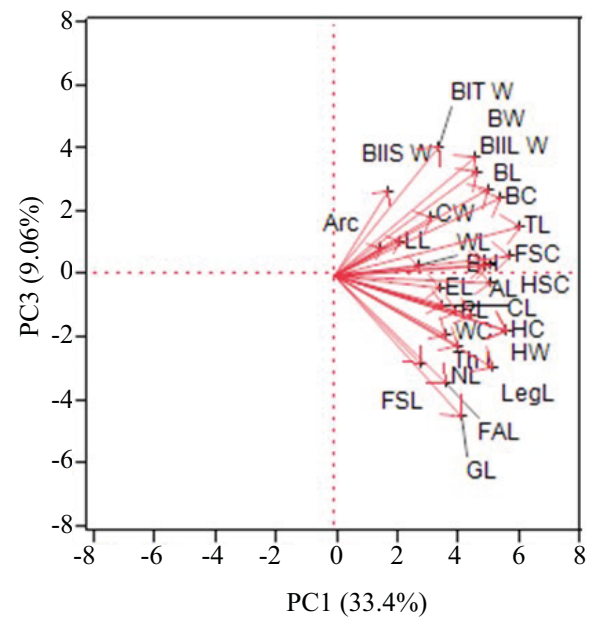

PC - Principal Component; HW - height at withers; HC - height at croup; BH barrel height; BW - barrel width; BL - barrel length; BC - barrel circumference; CW - chest width; TL - trunk length; CL - croup length; BIIL W - bi-iliac width; BIT W - bitrochanteric width; BIIS W - bi-ischial width; FSC - foreshank circumference; HSC - hind shank circumference; Arc - arc length; NL - neck length ; WC - withersto-croup distance; LL - loin length; WL - withers length; AL - arm length; FAL forearm length; FSL - foreshank length; Th L - thigh length; GL - gaskin length; PL pastern length; Leg L - leg length; EL - ear length.

Figure 8 - Load plot of jennet biometrics for areas: PC1 vs PC3.

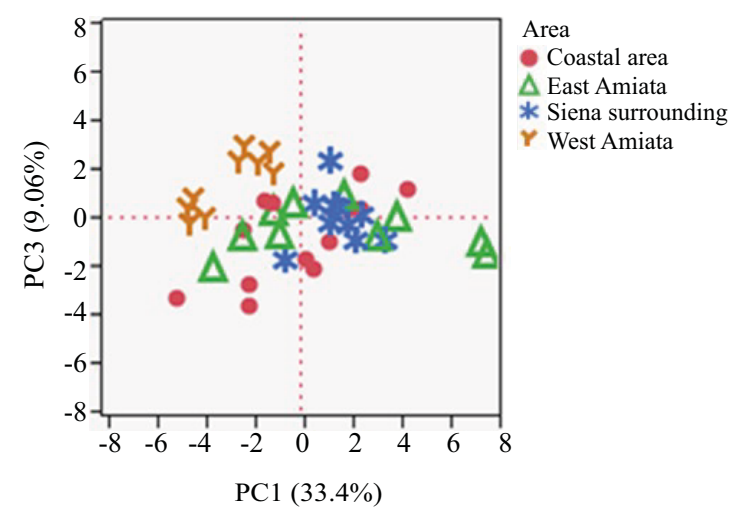

PC - Principal Component.

Figure 9 - Score plot of jennet biometrics for areas: PC1 vs PC3.

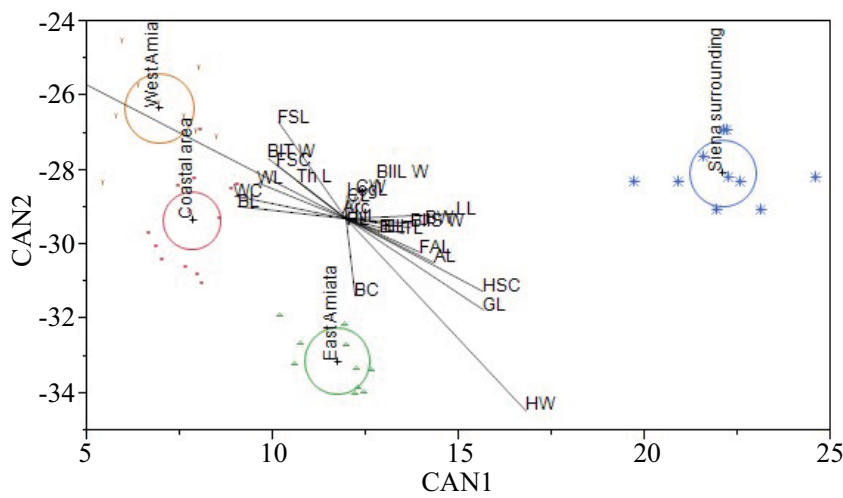

HW - height at withers; HC - height at croup; $\mathrm{BH}$ - barrel height; $\mathrm{BW}$ - barrel width; $\mathrm{BL}$ - barrel length; BC - barrel circumference; CW - chest width; TL - trunk length; $\mathrm{CL}$ - croup length; BIIL W - bi-iliac width; BIT W - bitrochanteric width; BIIS W bi-ischial width; FSC - foreshank circumference; HSC - hind shank circumference; Arc - arc length; NL - neck length; WC - withers-to-croup distance; LL - loin length; WL - withers length; AL - arm length; FAL - forearm length; FSL - foreshank length; Th L - thigh length; GL - gaskin length; PL - pastern length; Leg L - leg length; EL - ear length.

Figure 10 - Biplot of canonical (CAN) discriminant analysis showing the first against the second canonical variant of the areas.

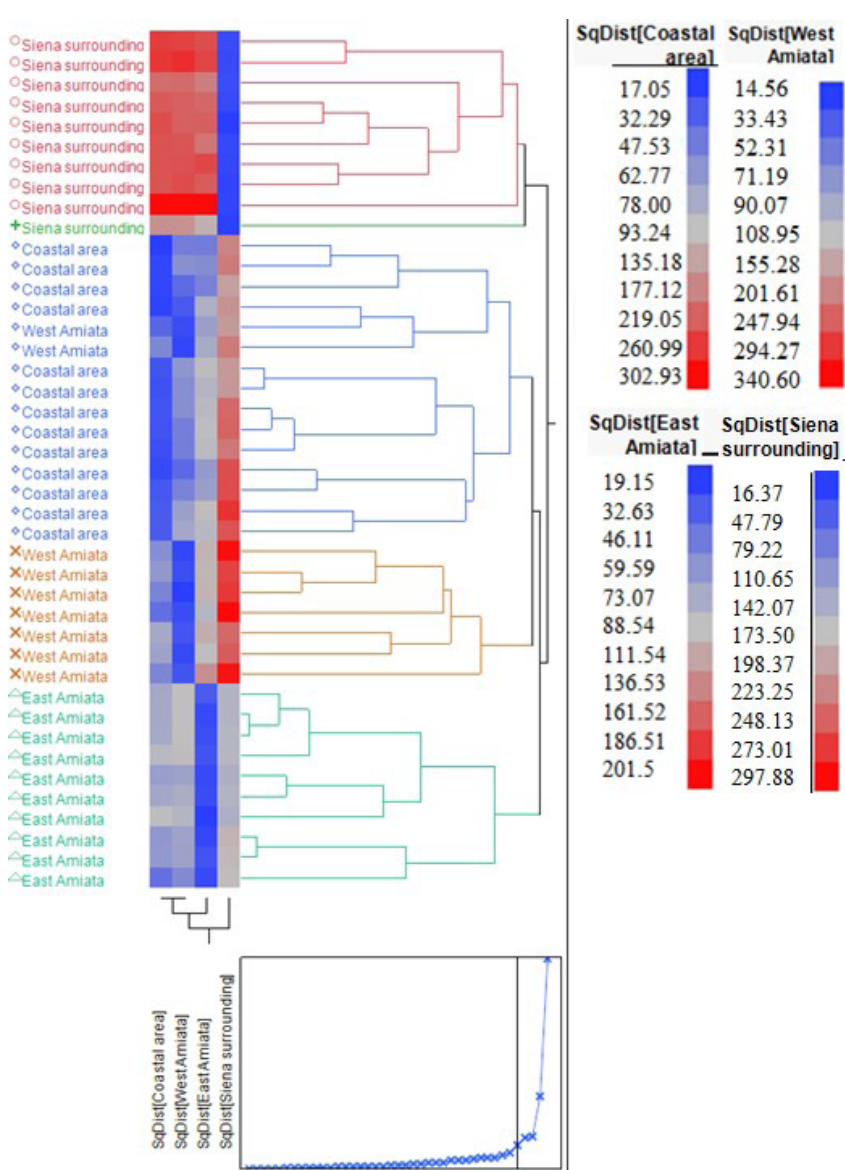

Figure 11 - Heatmap of the square distance among donkey populations. 


\section{Conclusions}

Amiata donkeys present the main ancestral coat characteristics: leg strips, found mainly in West Amiata, Siena surrounding, and Coastal area, and zippers, found in East Amiata and Coastal area donkeys. The West Amiata population has smaller individuals, probably selected in the past for mining works. Principal Component Analysis and Canonical Discriminant Analysis separate Siena surrounding jennets from the other groups based on different heights and lengths, and such animals are more suitable for saddle, trekking, and milk production. The different biometrics found in this study will be more homogeneous in the future through the selection and the diffusion of the breed.

\section{Acknowledgments}

The authors wish to thank private and state donkey breeders. This work was supported by Regione Toscana, Dir. Gen. Sviluppo Economico.

\section{References}

Abdi, H. and Williams, L. J. 2010. Principal component analysis. Wiley Interdisciplinary Reviews: Computational Statistics 2(4):433-459. https://doi.org/10.1002/wics.101

AIA - Associazione Italiana Allevatori. 2013. Available at: <http:// www.aia.it/CMSContent/DM_25420_RA_Equini(1).pdf $>$. Accessed on: Jan. 16, 2018.

Arzilli, L. 2006. Asino dell'Amiata. Risorse genetiche animali autoctone della Toscana. ARSIA, Firenze. p.29-33.

Beretti, V.; Zanon, A.; Soffiantini, C. S. and Sabbioni, A. 2005. Preliminary results about morphological and demographic traits of Romagnolo donkey. Annali della Facoltà di Medicina Veterinaria 25:131-144.

Camillo, F. 2011. "Approccio multidisciplinare alla conservazione dell'Asino dell'Amiata: riproduzione, allevamento e genetica". Progetto di ricerca PRIN 2004.

Catalano, A. L. 1984. Valutazione morfo-funzionale del cavallo Igiene ed Etnologia. Goliardica Editrice, Noceto, Parma, Italy.

Cecchi, F.; Ciampolini, R.; Ciani, E.; Mazzanti, E.; Tancredi, M. and Presciuttini, S. 2007. Morphological characterization of the Amiata donkey breed through the data reported in the Anagraphic Register. Italian Journal of Animal Science 6(suppl. 1):70.

Civardi, G. 2004. Studio del latte di equidi in funzione del suo utilizzo in alimentazione umana. Ph D Diss. In "Produzioni animali, sanità e igiene degli alimenti nei paesi a clima mediterraneo" (A.Y. 2000). Facoltà di Medicina Veterinaria - Università di Pisa.

Haarman, B. C. M.; Riemersma-Van der Lek, R. F.; Nolen, W. A.; Mendes, R.; Drexhage, H. A. and Burger, H. 2015. Featureexpression heat maps: a new visual method to explore complex associations between two variable sets. Journal of Biomedical Informatics 53:156-161. https://doi.org/10.1016/j.jbi.2014.10.003

Jackowski, M. 2007. Przypadek - moda - a może sukces kilku fachowców. Hodowca i Jeździec 12:17-21.

Johnson, S. and Johnson, D. 2008. Horse breeds. Voyageur Press, Minneapolis, MN.

Kaiser, H. F. 1960. The application of electronic computers to factor analysis. Educational and Psychological Measurement 20:141151. https://doi.org/10.1177/001316446002000116.

Karatosidi, D.; Marsico, G. and Tarricone, S. 2013. Modern use of donkeys. Iranian Journal of Applied Animal Science 3(1):13-17.

Kefena, E.; Beja-Pereira, A.; Han, J. L.; Haile, A.; Mohammed, Y. K. and Dessie, T. 2011. Eco-geographical structuring and morphological diversities in Ethiopian donkey populations. Livestock Science 141:232-241. https://doi.org/10.1016/j. livsci.2011.06.011

Kost'uková, M.; Černohorská, H.; Bihuncová, I.; Oravcová, I.; Sobotková, E. and Jiskrová, I. 2015. Characteristics of morphological parameters of donkeys in the Czech Republic. Acta Universitatis Agriculturae et Silviculturae Mendelianae Brunensis 63:419-424. https://doi.org/10.11118/actaun201563020419

Kugler, W.; Grunenfelder, H. P. and Broxham, R. 2008. Donkey breeds in Europe: inventory, description, need for action, conservation. Report 2007/2008. SAVE Foundation.

Lenfant, C. 1973. High altitude adaptation in mammals. Amerigcan Zoologist 13:447-456.

Martini, M.; Altomonte, I. and Salari, F. 2014. Amiata donkeys: fat globule characteristics, milk gross composition and fatty acids. Italian Journal of Animal Science 13:123-126. https://doi.org/10.4081/ijas.2014.3118

Meregalli, A. 1980. Conoscenza morfofunzionale degli animali domestici. Liviana Ed., Padova, Italy.

Ragona, G.; Corrias, F.; Benedetti, M.; Paladini, I.; Salari, F.; Altomonte, I. and Martini, M. 2016. Amiata donkey milk chain: animal health evaluation and milk quality. Italian Journal of Food Safety 5(3):5951. https://doi.org/10.4081/ijfs.2016.5951

Samorì, C. 2017. Maurizio e i suoi asini "terapeutici” per le persone con disabilità. Available at: $<\mathrm{http} / /$ sociale.corriere.it/maurizio-ei-suoi-asini-terapeutici-per-le-persone-con-disabilita/>. Accessed on: Jan. 16, 2018.

Sargentini, C.; Tocci, R.; Lorenzini, G.; Gianangeli, B.; Martini, A.; Gallai, S. and Giorgetti, A. 2009. Morphological characteristics of Amiata donkey reared in Tuscany. Italian Journal of Animal Science 8 (Suppl. 2):721-723. https://doi.org/10.4081/ ijas.2009.s2.721

Sargentini, C.; Tocci, R.; Andrenelli, L. and Giorgetti, A. 2012. Preliminary studies on hoof characteristics in Amiata donkey. Italian Journal of Animal Science 11:e22. https://doi.org/10.4081/ ijas.2012.e22 